Cinco radios de La Plata en tiempos de coronavirus

Carlos Milito - Sergio Antonucci - Marcelo Martín Gisande - Gustavo Castro García - Eduardo Capdevilla - Nicolás Sampedro - Verónica Porrini - Nahuel Espinoza - Ayelén Berdiñas - Sonia Negrin - Federico Manzi - Vito Gerardo Ascolese - Fernando Iranzo

https://doi.org/10.24215/16696581e368

\title{
Cinco radios de La Plata en tiempo de coronavirus Informe de avance
}

\section{Five radios of La Plata in coronavirus time Progress report}

\begin{abstract}
Equipo de investigación del Taller de Producción de Contenidos y Narrativas Sonoras y Radiales Facultad de Periodismo y Comunicación Social-UNLP

Carlos Milito
https://orcid.org/0000-0002-5874-6951 cmilito@perio.unlp.edu.ar Magister en Comunicación y gestión de procesos comunicacionales FPyCS UNLP Profesor Titular del Taller de producción de contenidos y narrativas sonoras y radiales Director de la Especialización en Comunicación radiofónica - FPyCS UNLP Coordinador de 1894radioonline de Villa Elisa, Provincia de Buenos Aires Locutor comercial de Relatores. Transmisiones Deportivas por la app y AM530 Somos Radio Integrante del IICom (Instituto de Investigaciones en Comunicación) FPCS UNLP
\end{abstract}

\author{
Sergio Antonucci \\ Lic. Comunicación Social. \\ Adjunto Cátedra Narrativas Sonoras. FP y CS \\ Investigador UNLP. \\ Productor de radio desde 1987. (Radio Universidad de La Plata AM 1390, Radio Provincia de Bs As, AM 1270, \\ FM 99.1, FM La Redonda 100.3 \\ RadioPerio (La radio web de la FPyCS UNLP
}

Marcelo Martín Gisande Periodista. Licenciado en Comunicación Social. Docente del Taller de Contenidos y Narrativas Sonoras y Radiales y del Seminario de Relato Deportivo. FPyCS-UNLP. Prensa en CONICET. En radio desde 1997 (FM La Redonda 100.3; Radio Universidad Nacional de La Plata AM 1390 y FM 107.5; entre otras), hoy en KEOPS FM 90.1.

Gustavo Castro García

Periodista y Licenciado en Comunicación Social. Universidad Nacional de La Plata. Docente ayudante de primera del Taller de Producción de Contenidos y Narrativas Sonoras y Radiales. Facultad de Periodismo y Comunicación Social. Universidad Nacional de la Plata. Integrante del Equipo de Prensa y Comunicación de la Asociación de Docentes de la Universidad de La Plata. 
Eduardo Capdevilla

Licenciado en Comunicación Social orientación Periodismo (UNLP); estudiante de Locución Integral (convenio UNLP ISER); docente dedicación simple Taller de Producción de Contenidos y Narrativas Sonoras y Radiales (Facultad de Periodismo y Comunicación Social UNLP); investigador universitario; ponente en seminarios del ensayo "Radio por aplicación: nuevos escenarios, identidades y desafíos de las prácticas de producción"; Jefe de Departamento de Gestión Del Conocimiento del Instituto Provincial de la Administración Pública (IPAP) de Buenos Aires ; columnista de programas de noticias en distintas emisoras regionales; colaborador en portales de noticias.

Nicolás Sampedro
Estudiante de la Lic. en Comunicación Social. Adscripto Cátedra Narrativas Sonoras FPyCS-UNLP

Periodista especializado en Política Internacional, conductor y productor de radio, y Editor de Revista Trinchera.

Verónica Porrini

Licenciada en comunicación social con orientación en planificación comunicacional (UNLP).

Docente ayudante diplomada del Taller de Producción de contenidos y Narrativas Sonoras, Facultad de Periodismo y Comunicación Social UNLP.

Integrante equipo de prensa y comunicación del Ministerio de Justicia de la Provincia de Buenos Aires. Docente del IPAP, Instituto Provincial para la Administración Publicación, en materias relacionadas a la comunicación institucional.

Nahuel Espinosa Lic. en Comunicación Social orientación Periodismo (UNLP). Docente ayudante diplomado del Taller de Producción de contenidos y Narrativas Sonoras, Facultad de Periodismo y Comunicación Social (UNLP)

Ayelen Berdiñas Licenciada en Comunicación Social (UNLP) Docente auxiliar del Taller de Producción de contenidos y narrativas Sonoras (FPyCS) y del Taller de Nuevos Lenguajes y Narrativas (FPyCS) Periodista. Productora Radio Cantilo y columnista Radio Provincia.

Sonia Negrin Investigadora categoría 4. Periodista/locutora. Esp en Comunicación Radiofónica. Trabaja en Radio Provincia. Redes Sociales y conductora de "Asuntos Pendientes"

Federico Manzi Licenciado en Comunicación Social, Especialista en Comunicación Radiofónica (UNLP). Locutor nacional, Profesor JTP Taller de producción de contenidos y narrativas sonoras y radiales. Docente Iser La Plata (ISFDYT 8), y DGCYE

Vito Gerardo Ascolese. Licenciado en Comunicación Social UNLP. Director de Derechos Humanos, presidencia de La Legislatura Provincia de Buenos Aires, 2011-2015. En la actualidad se desempeña como periodista reportero y redactor en LS11 Radio Provincia de Buenos Aires, cargo que ejerce desde 1983. Es docente de la Facultad de Periodismo y Comunicación Social de La Plata.

Fernando Iranzo Licenciado en Comunicación Social, orientación Periodismo. Locutor Nacional 12.555. Docente del Taller de Producción Radiofónica I

\section{Resumen}

Durante la vigencia del aislamiento social preventivo y obligatorio dispuesto por el Gobierno Nacional Argentino a raíz de la pandemia del COVID-19, los consumos culturales se han visto impactados por nuevas modalidades, y la radio ha sido consecuente con su rol de informar e 
interpretar lo que sucede en una sociedad, acosada por la pandemia. La investigación indaga en los modos de organizar la comunicación de la Pandemia en cinco radios de la ciudad.

\section{Palabras Claves}

Radios - cobertura periodística - rutinas de producción - pandemia - gestión de la información - noticias - teletrabajo -

\section{Summary}

During the term of the preventive and mandatory social isolation provided by the Government Argentine National National As a result of the COVID-19 pandemic, cultural consumption has been impacted by new modalities, and radio has been consistent with its role ininforming and interpreting what is happening in a society, bewn by the pandemic. The research investigates ways to organize the communication of the Pandemic in five radios in the city.

\section{Keywords}

Radios - journalistic coverage - production routines- pandemic - information management news - telework -

Radio Cantilo: https://ar.ivoox.com/es/51718335

Radio Cielo: https://ar.ivoox.com/es/51718364

Radio Estación Sur: https://ar.ivoox.com/es/51718442

Radio La Redonda: https://ar.ivoox.com/es/51718556

Radio Provincia: https://ar.ivoox.com/es/51718626

Radio Universidad: https://ar.ivoox.com/es/51718740 


\section{La radio en emergencia}

"La radio puede ser un salvavidas en tiempos de crisis y emergencia. En sociedades devastadas, azotadas por la catástrofe o que necesitan noticias desesperadamente, la gente encuentra en la radio la información que salva vidas. (...) La radio puede ser útil en operaciones de respuesta de emergencia y ayudar a la reconstrucción" Ban Ki-Moon, Secretario General de la ONU, en su discurso del Día Mundial de la Radio, 2016.-

Durante la vigencia del aislamiento social preventivo y obligatorio dispuesto por el Gobierno Nacional Argentino a raíz de la pandemia del COVID-19, los consumos culturales se han visto impactados por nuevas modalidades, y la radio ha sido consecuente con su rol de informar e interpretar lo que sucede en una sociedad, acosada por la pandemia.

El papel fundamental que tuvo la radio en catástrofes naturales como los últimos huracanes que azotaron Cuba, Puerto Rico y otras islas del Caribe, el terremoto de México o el tsunami de Chile son la prueba evidente y reiterada una vez más de que en momentos de incertidumbre absoluta, cuando los servicios más esenciales fallan por falta de suministro eléctrico, "la radio es el único medio que ofrece foco y contexto, acompaña, consuela, ayuda, tranquiliza, divierte $y$ alivia"..

Si observamos lo que ocurre en España uno de los países más duramente afectados por la pandemia, "La radio lidera el ranking de medios más fiables en la crisis del coronavirus".ii Así lo confirma un estudio realizado por la agencia y consultora Havas Media Group, el pasado 19 de marzo.

"La elección de la radio como medio más consultado es, sin embargo, generacional: confían en él, sobre todo, los hombres a partir de los 40 años. El estudio constata que la preocupación de los ciudadanos ante el coronavirus se sitúa, en el 75 por ciento de los casos y aumenta con la edad. Como consecuencia de la preocupación, ha aumentado la demanda de la información más veraz y rigurosa, y en esa clasificación la radio sale la mejor parada, seguida muy de cerca de la televisión y la prensa; es decir, los medios tradicionales frente a las redes sociales, mucho más implantadas entre las generaciones más jóvenes. 
La radio revalida su credibilidad como medio. El Eurobarómetro, la herramienta de la Unión Europea para medir el estado de la opinión pública de los ciudadanos europeos, confirma en cada estudio que la radio es el medio más creíble para ellos, y el que más destaca en su papel fundamental ante la desinformación.

En un tiempo en que lo digital arrecia, en que las nuevas generaciones le dan la espalda ante la falta de contenidos y tono que le atraigan, en que lo que se impone es lo moderno, frente a lo antiguo, y amortizado, la radio resiste todo tipo de embates, y hoy, en las casas españolas, la radio vuelve a convertirse en el altar de la información más rigurosa y veraz, y en la oportunidad de que los jóvenes, nuevamente expuestos a su escucha como oyentes cautivos familiares, la valoren como se merece.

En tanto, en su peor momento, en la Italia arrasada por el virus, todas las emisoras pasan el himno a la misma hora. Con los servicios de salud desbordados y miles de familias que no pueden despedir a sus seres queridos, desde la radio una voz imperativa se hace eco: “¡Restate a casa, cazzo!” (¡Quédate en casa, carajo!).

En Argentina en los últimos meses la radio una vez más ha dado pruebas de que en momento de crisis, vuelve a recuperar el protagonismo que algunos daban por perdido.

El domingo 16 de junio de 2019, un apagón masivo a nivel nacional dejó a celulares, tablets y las casi en desuso PC de escritorio fuera de toda utilidad, y fueron los clásicos aparatos de radio y sus transmisiones analógicas las que permitieron llevar información y certezas a la población desconcertada acerca de qué estaba sucediendo.

En La Plata todas y todos recordamos sin duda el papel destacado y articulador que tuvieron las radios locales durante la trágica inundación del 2 de Abril de 2013.

En esta oportunidad no es por ausencia de otros medios sino porque la radio mantiene intacta su confiabilidad y sigue siendo el medio mayoritariamente sintonizado por las audiencias a la hora de informarse.

Según Agustín Espadaiii "En cuanto a los consumos sonoros-radiofónicos, los únicos datos disponibles nos permiten registrar las visitas diarias a sus sitios web. Allí encontramos algunos aumentos como los de El Destape (95\%), Futurock (93\%), Radio Con Vos (66\%), Metro (53\%) y Cadena 3 (40\%). Algunas otras cayeron en visitas, como Aspen (-14\%), Los 40 (-15\%) y Cien 
Radios, que incluye a Mitre y La 100 (18\%), aunque eso no quiere decir que se escuchen menos.

En tiempo de cuarentena y aislamiento, los hábitos cambian. La información en medios tradicionales, mientras el entretenimiento parece centrarse en lo audiovisual y las redes sociales. Los portales crecen y muchas radios muestran crecimiento en sus conexiones online. La cuarentena, al parecer, tendrá al público entretenido e informado".

Con sus estudios despoblados, las radios en general mantienen sus programaciones con el personal mínimo necesario desde las emisoras, mientras que conductores, columnistas, movileros, productores, editores de redes sociales, informativistas y locutores trabajan desde sus casas. En algunos casos, sólo un operador y un productor por turno son necesarios en piso.

"Desde la cuarentena total y obligatoria, los programas se llenaron de ruidos domésticos. El sonido óptimo quedará como requerimiento para otra era. Lo que importa es informar y los periodistas y columnistas lo hacen desde sus casas, con ladridos de perros de fondo, llantos de hijos, ruidos de aspiradoras. Las emisoras toman la fiebre de sus empleados en los umbrales. Los micrófonos se bañan de alcohol en gel. Las consolas se desinfectan y los papeles manuscritos se evitan, afirma Marina Zucciiv, periodista de Clarín.

Golpeadas por la recesión económica y las políticas neoliberales seguidas por el macrismo a partir de 2015, las radios vienen atravesando una situación crítica desde mucho antes que se declarara la pandemia.

Con los planteles reducidos desde hace varios años y cientos de trabajadores reclamando salarios atrasados e indemnizaciones adeudadas, la radiofonía argentina ha visto desaparecer emisoras tradicionales y las que han logrado sobrevivir lo han hecho modificando sus propuestas comunicacionales y adaptándose a las características de un mercado dinámico, multimedial y devastador.

En ese contexto se trabaja hoy para las nuevas audiencias. Sin embargo, el grupo etario tradicional oyente de las frecuencias de AM constituye la población más vulnerable al virus, y por tanto las programaciones vuelven a incorporarlos como destinatarios fundamentales de los contenidos que se producen a diario.

A modo de ejemplo, Matías Martin, en Metro 95.1 reforzando una sección estrenada hace años denominada "Llamá a tus abuelos", Aspen con sus clásicos serenos como propuestas de 
meditación musical, El Rotativo del aire -inmutable desde 1959- se vuelve moderno y Mitre informa primero es banda sonora de los supermercados. Radio Provincia de Buenos Aires en sus dos frecuencias y sin programación al aire ensaya música y noticias sólo interrumpida por las conferencias de prensa de funcionarios gubernamentales, Nacional sumando a su grilla programas educativos para reforzar las aulas virtuales.

En el marco del \#QuedateEnCasa, la misión y el desafío para la radio se ha renovado pero con la certeza de consolidar la función informativa, la interpretación seria y a intermediación responsable.

\section{Los programas especiales de Emergencia}

Las producciones especiales de emergencia, son realizaciones que irrumpen en la programación de una emisora a partir de una situación o acontecimiento especial o inédito. La UNESCO en su Manual de Gestión de Riesgos de Desastre para Comunicadores Sociales (2011), indica que el desastre está vinculado con una alteración en el normal funcionamiento de la sociedad que deviene del impacto generado por un fenómeno de origen natural, biológico o causado por la acción del hombre. Algunos ejemplos: la inundación de la ciudad de La Plata, o el Coronavirus a nivel planetario.

Los programas especiales de Emergencia se diseñan ante una excepcionalidad radical. Son producciones que aparecen en cualquier momento, y pueden sostenerse por un tiempo limitado mientras dura una emergencia.

La relevancia del tema necesita de la comunicación precisa y rigurosa, basada en una capacidad de investigación "en tiempo real", la comprensión del problema y las sugerencias que propongan una perspectiva humanista, un esquema de reflexión que interprete críticamente y de manera propositiva lo que sucede, que oriente decisiones de la vida cotidiana transformada, proponga actividades, anticipe dificultades, bajo un paraguas preventivo y sostenga un clima de contención y fortaleza del humor social.

Argentina editó la Guía para la cobertura periodística responsable de desastres y catástrofes, que fue elaborada por la Defensoría del Público (2013). El trabajo sistematiza recomendaciones y criterios sobre el rol de los medios audiovisuales durante una situación de emergencia. Esta producción de la Dirección de investigación, monitoreo y análisis de la Defensoría del Público de Servicios de Comunicación Audiovisual reunió los aportes 
construidos en diversas mesas de trabajo de las que participaron periodistas, productores, camarógrafos, movileros, sindicatos de trabajadores de medios y redes de comunicación. Atravesada la crisis del COVID-19 habrá que contrastar este inmejorable aporte, considerando al menos las nuevas rutinas remotas que han impactado en las emisoras.

Según Cebrián Herreros, "Son programas que requieren una enorme agilidad de la emisora para improvisar en un tiempo escaso una información de alta calidad; al tratarse de hechos complejos es necesario que toda la redacción se entregue a su colaboración de manera inmediata para recopilar la mayar cantidad de datos y de mejor calidad para ofrecer a la audiencia un producto bueno. Es un programa que mide la capacidad creativa, de rapidez y de improvisación de una emisora"v

En tiempos del coronavirus las radios han modificado sus grillas con Programas especiales de Emergencia, no obstante han sostenido los regulares alterando sus contenidos a partir del incidente del virus.

Este encuadre amplio, propuso el Taller de producción de contenidos y narrativas sonoras y radiales, para revisar que sucede en las radios de la ciudad de La Plata. El Equipo seleccionó cinco (5) emisoras para indagar cómo se posicionaron en la cobertura de la pandemia. Las radios enfocadas fueron: Radio Universidad Nacional de La Plata, Radio Provincia de Buenos Aires, Radio Cantilo, Radio Estación Sur y La Cielo. 


\section{EI COVID-19 en las frecuencias de las diagonales}

\section{Radio Universidad Nacional de La Plata}

En la radio de la Universidad Nacional de La Plata, a partir de la declaración del aislamiento se modificaron las prácticas profesionales cotidianas de las emisoras, porque las políticas de prevención han disminuido al mínimo los planteles en la sedes físicas de las radios y se han implementado rutinas de transmisiones a distancia con buena parte de la estructura periodística, técnica y de gestión desde sus hogares. Una situación nueva para la ejecución de las transmisiones de emergencia.

Al mismo tiempo en Radio Universidad de La Plata se ha suspendido la programación regular, se emite música y boletines y se planificaron tres programas especiales de emergencia sobre COVID-19 de dos (2) horas de duración. Uno por la mañana de10.00 a 12.00, otro por la tarde de 14.00 a 16.00 y el último de 18.00 a 20.00 .

El avance de la pandemia, la respuesta del Estado y sus regulaciones, las mismas normativas de la Universidad y la maduración objetiva de lo que sucedía, retrasó en un poco más de una semana, la puesta en marcha de una programación de emergencia que facilitara desde la comunicación radiofónica y el periodismo la comprensión de lo crisis y orientara decisiones. En esos días, el aire se ocupó con música, boletines y pastillas temáticas.

Los programas especiales de Emergencia podrían pensarse como un sub-formato del Programa Especial. En estas circunstancias es indispensable modular la información, la opinión y la intermediación (Transmisión de solicitudes de ayuda, cotejo de versiones, transmisión de quejas y demandas, impugnación de decisiones, acopio, represión estatal, etc.) para procurar acompañar una reorganización posible del mundo cotidiano, darle un sentido racional y afectivo a la realidad, donde la virtualidad se ha impuesto y volver entendible lo que nos sucede para tener perspectiva y estar dispuesto a participar de un futuro inmediato lo más aclarado posible, individual y colectivamente.

\section{Identificación de la radio}

\begin{tabular}{|c|c|}
\hline Nombre de la Emisora & $A \mid M / / F$ \\
\hline IIpo de EmIsora & Estatal \\
\hline I ransmite por Streamıng & Direccion: nttps://www.radiouniversidad.unip.edu.ar/ \\
\hline Redes Soclales & recebook. Instagram. I witter. \\
\hline
\end{tabular}




\begin{tabular}{|l|l|}
\hline Nombre del Programa a analizar & $\begin{array}{l}\text { Sin nombre } \\
\text { No hay una artística específica }\end{array}$ \\
\hline Intormatıvo & Intormativo Radio Universidad. Boletin cada 1 hora \\
\hline
\end{tabular}

\section{El programa}

\begin{tabular}{|c|c|c|}
\hline & Precisiones & Ubservaciones /aciaraciones \\
\hline Nombre & Sin nombre & Sin artistica. \\
\hline Horarıo & 10.00 a 12.00 & \\
\hline $\begin{array}{l}\text { Integrantes del Equipo y } \\
\text { Roles }\end{array}$ & $\begin{array}{l}\text { Conductor: Marcos Clavelino } \\
\text { Co-Conductor: Matías Bongiovani }\end{array}$ & $\begin{array}{l}\text { Se integran periodistas de la emisora con intormes y } \\
\text { comentarios. Ej. El movilero, Ezequiel Lasta sale } \\
\text { desde su casa y recupera audios (declaraciones de } \\
\text { funcionarios de la UNLP) para su intervención. }\end{array}$ \\
\hline Contenidos desarrollados & \multicolumn{2}{|c|}{$\begin{array}{l}\text { Aborda tema Coronavirus desde distintas perspectivas. } \\
\text { El cuidado de la salud en pandemia, } \\
\text { Las organizaciones sociales y sus formas de articulación para el cuidado y la } \\
\text { prevención. } \\
\text { Análisis matemático sobre la curva de crecimiento de la enfermedad. } \\
\text { Compromiso de las estructuras de la UNLP para el cuidado de la sociedad } \\
\text { Servicios. Apertura de Bancos para la atención de jubilados y beneficiarios de la } \\
\text { tarjeta alimentaria. }\end{array}$} \\
\hline Genero & Periodistico & \\
\hline Formato & IVagazın & \\
\hline Duracion & 120 minutos/ 2 horas & \\
\hline Breve descripcion tematica & $\begin{array}{l}\text { El programa especial aborda el tema de } \\
\text { COVID-19 desde distintas disciplinas y } \\
\text { prácticas sociales. }\end{array}$ & \\
\hline $\begin{array}{l}\text { Entrevistados } \\
\text { Comentarista } \\
\text { Móvil } \\
\text { Conductor } \\
\text { Otros. Precisar }\end{array}$ & $\begin{array}{l}\text { SI } \\
\text { Sí } \\
\text { No } \\
\text { Sí } \\
\text { Operadores de estudio y planta transmisora } \\
\text { Comunicador a cargo de Redes Sociales }\end{array}$ & \\
\hline $\begin{array}{l}\text { EI programa tIene una } \\
\text { versión a la carta en un sitio } \\
\text { web }\end{array}$ & No & \\
\hline Descripcion de la propuesta & Comunican sobre la pandemıa e Intormacion & \\
\hline
\end{tabular}




\begin{tabular}{|l|l|l|}
\hline $\begin{array}{l}\text { comunicativa en las redes } \\
\text { sociales. }\end{array}$ & Cultural y de entretenimientos & Ubservaciones /aciaraciones \\
\hline
\end{tabular}

\section{En redes sociales}

En la actualidad la Radio Universitaria platense utiliza tres redes sociales; Twitter, Facebook e Instagram.

La red social que más seguidores tiene es Twitter, cerca de 20000, le sigue Facebook con 7000 y por último Instagram, que es la que más tarde se incorporó y la que más crecimiento tuvo en el último año, duplicándose los usuarios; cuenta con 3300 seguidores.

\section{Twitter:}

En la actualidad esta red social es la que más seguidores suma, pero paradójicamente la que menos presencia tiene con contenidos propios de la radio. Las publicaciones son replicaciones de contenidos de diferentes dependencias de la Universidad Nacional de La Plata.

En este contexto social de pandemia por ejemplo, publican cómo adaptaron cada una de las Universidades las actividades académicas a la situación de cuarentena obligatoria; como así también los aportes sobre investigación y publicaciones científicas sobre el avance, control y prevención del Covid-19.

Se utiliza mucho el retwiteo para actividades de las diferentes Universidades, y en algunos casos (no es lo habitual) se publica algún contenido propio sobre notas producidas en la radio.

\section{Instagram:}

Los posteos de Instagram son de los anuncios de los contenidos que tratarán en los diferentes programas, promoción de la programación o anuncio del programa que saldrá al aire.

Un ejemplo: en esta situación de pandemia, todos los miércoles a la noche se lee un cuento literario que es fraccionado en varias partes y es leídos por diferentes personalidades; esto se anuncia y se promueve para convocar a los interlocutores a escuchar la propuesta de los miércoles.

\section{Facebook:}

Esta red es una de las más utilizadas. Se anuncia la programación y se comparten las notas más destacadas realizadas en la radio durante ese día. Se promueven programas y la participación de invitados especiales. 
Lo que sucede con esta red es que muchos usuarios ponen "me gusta" en alguna de las publicaciones sin transformarse en seguidores, sino lo hacen en la Fanpage.

Algo particular que se instaló en esta situación de pandemia, tanto en Instagram como en Facebook, es la incorporación de videos con personalidades reconocidas de la cultura, que recomiendan lecturas, actividades, series y pasatiempos para atravesar la cuarentena.

En las historias de Instagram y Facebook se publican sólo aquellas de producción propia, de programas o de algún profesional de la radio. No se publican historias de usuarios, aún cuando éstos etiqueten a la radio, estas historias o etiquetas no se comparten. Los posteos de Facebook e Instagram son entre dos y cuatro por día, o sea nunca menos de dos, pero tampoco más de cuatro. Siempre en los mismos horarios.

En un primer momento con el inicio del aislamiento social obligatorio, las redes sociales fueron utilizadas para difundir la nueva programación. En una segunda etapa se gestionaron las redes para difundir audios de diferentes personalidades de la cultura para recomendar actividades, películas y lecturas, como hemos mencionado. Posteriormente comenzaron a subir contenidos más específicos sobre el tratamiento periodístico del Corona Virus (entrevistas, informes, etc.) 


\section{Radio Provincia de Buenos Aires}

En el momento de la realización de este relevamiento la emisora solamente emitía programación musical que comenzó con el barrido del aire, a principio del mes de Marzo.

La medida del "barrido" se adoptó para dar inicio a la nueva grilla de contenidos correspondiente a la nueva gestión del actual director, Marcelo Figueras. Por este y otros motivos se le adjudica la responsabilidad a la nueva gestión de la emisora, respecto de diseñar una programación especial, que se materializó diez días después de declarada la emergencia sanitaria y posterior cuarentena.

Durante el mes de marzo, en la frecuencia de la AM la programación fue exclusivamente musical con informativos cada media hora y a partir del miércoles 1 de Abril, comenzó a transmitirse de 8 a 10 de la mañana un único programa destinado a la emergencia, "Buenos Aires se Conecta".

El espacio conducido por la periodista Rocío López, tuvo contenidos exclusivamente relacionados a la situación que generó la pandemia en la Provincia de Buenos Aires en particular y en Argentina y el mundo en general. La presentación, los comentarios y las entrevistas realizados fueron acordes a los objetivos propuestos para el espacio. Se realizaron notas a integrantes del gabinete ministerial del gobierno bonaerense, la Ministra de Género y Diversidad de la Provincia y al Ministro de Obras Públicas bonaerense, por citar algunas. También fueron consultados funcionarios nacionales y provinciales a cargo de áreas de cobertura social. También contactaron a la mayoría de los periodistas, corresponsales, movileros que la emisora posee en distintos puntos estratégicos y comentaristas desde la Ciudad de Buenos Aires y La Plata.

Durante la mañana se transmitieron boletines informativos cada 30 minutos como corresponde a los días hábiles.

Al finalizar el programa se difundieron los contenidos grabados del Ministerio de Cultura y Educación de la Nación. La programación que sigue es educativa para el Nivel Inicial, de 10 a 11hs; Nivel Primario (Primer Grado), de 11 a 12hs; Segundo y Tercer Grado, de 12 a 13hs; Cuarto y Quinto Grado, de 13 a 14hs; Sexto y Séptimo Grado, de 14 a 15hs; Nivel Básico Secundario (segundo, tercero y cuarto año), de 15 a 16hs; y Ciclo Orientado Secundario (cuarto y quinto año), de 16 a 17hs. "Seguimos Educando" cuenta con el portal educativo on- 
line seguimoseducando.gob.ar que permite continuar en casa la tarea del aula con actividades, videos, libros digitales, series y otros contenidos del portal Educ.ar, y de los canales Encuentro, Pakapaka y DeporTV.

La programación de emergencia se transmitió de lunes a viernes por las frecuencias unificadas de AM y FM simultáneamente. Los sábados y domingos se puso al aire una selección musical e informativos cada hora con información vinculada a la pandemia.

Sobre la difusión de los boletines informativos y las promociones se observó que:

El informativo de las 8.00 es el primero de la jornada.

Se emiten cada hora de 8.00 a 20 todos los días. Los días hábiles y feriados cada media hora, sábados y domingos cada hora.

Al finalizar cada boletín por lo general continúa una tanda referida a la fusión de aire de las dos frecuencias $\mathrm{AM}$ y $\mathrm{FM}$ y a los 15 minutos se pudieron oír las promociones de la nueva programación que vendría después del barrido del aire, y las campañas preventivas correspondientes a la pandemia de Covid-19.

La ubicación de las promociones a lo largo de la programación no es uniforme en el tiempo, en los distintos días de escucha no se transmitieron en los mismos horarios. El lunes estaban ubicadas inmediatamente finalizada la lectura del boletín a la hora en punto y a los 30 minutos, y el martes la puesta al aire fue irregular pero continua en el tiempo. Los contenidos de las mismas están vinculados al cambio de programación inminente, y a la prevención ante la pandemia de Covid-19.

La programación de emergencia fue propuesta por los trabajadores de Radio Provincia y la gestión de la emisora decidió poner al aire un programa para esos fines durante la mañana, conducido por una de las periodistas desde la casa.

Los boletines informativos continuaron emitiéndose, cada media hora, pero con contenido casi exclusivo sobre la pandemia.

Por el aislamiento hubo que adaptar el trabajo presencial a la modalidad a distancia, a través de las redes, de esta manera incorporar una nueva mecánica de relación con el resto de los trabajadores de la emisora para poner al aire lo producido. Hubo algunos inconvenientes que sortear, todos vinculados a la implementación de las nuevas técnicas utilizadas para el trabajo a distancia y la posterior puesta al aire. 
Los comunicadores se mantuvieron al aire con los máximos cuidados correspondientes al aislamiento obligatorio. Nunca se perdió el objetivo de servicio destinado a informar a la audiencia. Esta nueva forma de trabajo exigió mayor destreza y una coordinación absoluta con el resto de los agentes vinculados a la puesta al aire de la programación, especialmente con los operadores y productores, al momento de manipular los cortes de audio, las notas e informes sonoros.

Con los locutores el envío del contenido impreso de la información se realizó a través del correo general del informativo, asegurándose también el reenvío a un correo personal. El formato del boletín es el mismo con el que se trabaja en época normal.

El equipo técnico desarrolló mediante distintas aplicaciones las soluciones que mejoraron la calidad de audio para la puesta al aire y resolvió otras situaciones que se fueron planteando en el desarrollo de las tareas.

La rutina presencial fue reemplazada por el teletrabajo y esto exigió la utilización de todos los recursos y programas que pudieran facilitar la comunicación. El wasap fue uno de los medios que agilizó el trabajo a través de los teléfonos celulares y de las computadoras.

Para la obtención de información a diario se consultan portales, páginas web y agencias de noticias, también las fuentes propias siguen aportando datos como sucede en todo momento del año.

A partir del inicio de la nueva programación el lunes 27 de abril de 2020, hubo que reasignar al personal de una manera más eficiente para cubrir las exigencias y demandas de los programas de aire.

Se trabaja en ternas de periodistas por vía remota con la participación de todos los integrantes del departamento informativo. La participación de los cronistas y corresponsales que trabajan a distancia fuera de la emisora, desde sus lugares destacados, sigue siendo la misma.

Se dispuso un periodista redactor de las informaciones para los boletines, otro que que realiza las escuchas de los programas que se ponen al aire y formaliza un extracto de las notas realizadas para integrarlas a los informativos y otro que recibe los informes de cronistas, corresponsales y movileros y luego de editarlos los dispone para ser incorporados a los boletines. 
El trabajo durante la pandemia y especialmente a distancia, dejará una impronta y revalorización del trabajo, una destreza y un aprendizaje de cómo utilizar las tecnologías disponibles para mejorar y agilizar la producción de contenidos.

\section{Identificación de la radio}

\begin{tabular}{|c|c|}
\hline Nombre de la emisora & $\begin{array}{l}\text { Radio Provincla de Buenos Aires } \\
\text { AM } 1270 \text { - FM } 97.1\end{array}$ \\
\hline IIpo & Estatal \\
\hline Iransmite por streamıng & nttp://radioprovincla.gba.gob.arl \\
\hline Redes Sociales & $\begin{array}{l}\text { nttps://www.tacebook.com/Provincial2/U } \\
\text { https://twitter.com/provincia1270 } \\
\text { https://www.instagram.com/provincia1270 }\end{array}$ \\
\hline Programa & "Buenos Alres se conecta" \\
\hline Intormativo & $\begin{array}{l}\text { Intorma Provincla. Cada } 30 \text { minutos en dias nabiles. Cada hora sabados y domıngos en las dos } \\
\text { frecuencias. }\end{array}$ \\
\hline
\end{tabular}

\section{El programa:}

\begin{tabular}{|c|c|c|}
\hline & Precisiones & Ubservaciones /aciaraciones \\
\hline Nombre & "Buenos Alres se conecta" & $\begin{array}{l}\text { Cortina de presentacion sin artistica con } \\
\text { promociones institucionales de prevención del } \\
\text { COVID19 }\end{array}$ \\
\hline Horarıo & Lunes a viernes de 8 a 10 & \\
\hline Equipo y roles & $\begin{array}{l}\text { Conduccion Rocio Lopez } \\
\text { Producción Cecilio Panella }\end{array}$ & $\begin{array}{l}\text { Cronistas acreditados en dependencias } \\
\text { gubernamentales y movileros }\end{array}$ \\
\hline
\end{tabular}




\section{Radio Cantilo}

La radio mantuvo los programas y segmentos habituales pero la pandemia de COVID-19 se convirtió en un eje transversal y estructural que marcó todos los espacios y los resignificó, haciendo que cada uno de estos abordara con su impronta la problemática de la pandemia, cumpliendo la función de informar y de servicio a los oyentes, tanto desde su emisión convencional como por la expansión de contenidos online por sitio web, aplicaciones o redes sociales.

En el programa de apertura de la primera mañana, los bloques en piso se estructuraron con la actualización de títulos y panorama global de la enfermedad; junto a las medidas dispuestas por el Estado en sus tres órbitas de acción y dispositivos de prevención del sistema sanitario.

La actualización de noticias y reportes de la enfermedad o acciones relacionadas con el combate al virus fueron informadas en el estudio por el conductor y la conductora, mientras que las ampliaciones o análisis ligados a cuestiones sanitarias, de impacto sociológico o economía, merecieron entrevistas o columnas de especialistas.

Una peculiaridad a mencionar es que la producción y realización de entrevistas o convocatoria a especialistas para columnas o análisis de aristas o secuelas de la pandemia, no contempló a funcionarios públicos.

Si bien el programa cumple la función y es el único de actualidad informativa en toda la grilla, la búsqueda, tanto para las secciones propias del programa como para las columnas o entrevistas pretende la reflexión distendida pero rigurosa.

Esto no sólo caracterizó a la estructura general del programa y a los segmentos habituales del mismo, sino que marcó la impronta del medio en las redes sociales y página web. Sobre los contenidos masivos de público conocimiento, el medio asumió el compromiso de agregar un plus con voces particulares, que desarrollaban un análisis sobre noticias para ampliar el servicio a los oyentes.

\section{Identificación de la radio}

\begin{tabular}{|c|c|}
\hline Nombre de la Emisora & FIVI CantIIO \\
\hline Frecuencia & $101.9 \mathrm{MHZ}$ \\
\hline I Ipo de EmIsora & Privada \\
\hline I ransmite por Streamıng & Direccion: https://www.radiocantllo.com/ \\
\hline Redes sociales & $\begin{array}{l}\text { nttps://www.tacebook.com/Radiocantllo/ } \\
\text { https://twitter.com/RadioCantiloOk }\end{array}$ \\
\hline
\end{tabular}




\begin{tabular}{|l|l|}
\hline & $\begin{array}{l}\text { https://www.Instagram.com/radlocantllo/ } \\
\text { https://vimeo.com/sybila } \\
\text { I otal normalldad }\end{array}$ \\
\hline Nombre del Programa a anallzar & No tiene \\
\hline IntormatIVO Nombre & \\
\hline
\end{tabular}

\section{El programa:}

\begin{tabular}{|c|c|c|c|}
\hline & Precisiones & \multicolumn{2}{|c|}{ Observaciones /aclaraciones } \\
\hline Nombre & \multicolumn{3}{|l|}{ Iotal normalıdad } \\
\hline Horarıo & \multicolumn{3}{|l|}{$1 \mathrm{a} 10$} \\
\hline Integrantes del equipo y roles & $\begin{array}{l}\text { Iapa conductor; } \\
\text { co-conductora Mariana De Iraola, columnista de } \\
\text { divulgación científica Manuel Carballeda, otra } \\
\text { de economía y servicios al consumidor, } \\
\text { Candelaria Blotto; de deportes, Camilo Santos; } \\
\text { y de cine, a cargo de colaborador de la radio. }\end{array}$ & \multicolumn{2}{|c|}{$\begin{array}{l}\text { Lenguaje descontracturado y dınamıco, con } \\
\text { referencias irónicas a las noticias pero } \\
\text { manteniendo el criterio de servicios. Invitan } \\
\text { en todo momento a los oyentes a participar } \\
\text { con anécdotas cotidianas para generar } \\
\text { empatía. }\end{array}$} \\
\hline Contenidos desarrollados. & $\begin{array}{l}\text { Evolucion de registros de la pandemia, medidas } \\
\text { oficiales, disposiciones del Poder Ejecutivo en } \\
\text { lo sanitario y económico; acuerdos con } \\
\text { autoridades provinciales y locales. Medidas de } \\
\text { prevención y estudios desarrollados, así como } \\
\text { el impacto del virus en la cotidianeidad y } \\
\text { producciones culturales. }\end{array}$ & \multicolumn{2}{|c|}{$\begin{array}{l}\text { Las intormaciones otıciales son reproducidas } \\
\text { de fuentes oficiales o portales y la ampliación } \\
\text { de sus contenidos con entrevistas o aportes } \\
\text { de especialistas. Respecto del impacto de la } \\
\text { enfermedad, se complementan las } \\
\text { entrevistas de analistas con el pedido a } \\
\text { oyentes para que colaboren vía mensajes de } \\
\text { WhatsApp, correos y otras vías virtuales.. }\end{array}$} \\
\hline Genero & Intormativo & & \\
\hline Formato & Entrevistas, columnas y comentarıos analıtıcos & & \\
\hline Duracion & \multicolumn{3}{|l|}{3 noras } \\
\hline Breve descripcion tematica & \multicolumn{3}{|c|}{$\begin{array}{l}\text { Los temas se abordan con comentarios analiticos, aportes de } \\
\text { especialistas o entrevistas y con interpelaciones a los oyentes y detalles } \\
\text { de sus aportes como datos en los bloques. }\end{array}$} \\
\hline $\begin{array}{l}\text { Entrevistados } \\
\text { Comentarista } \\
\text { Movil } \\
\text { Conductor } \\
\text { Otros. Precisar }\end{array}$ & \multicolumn{3}{|c|}{$\begin{array}{l}\text { Entrevistas: Nicolas UISzevickI, clentıtico del Conıcet, Ezequiel Kopel, } \\
\text { analista internacional; Richard Coleman, músico; ex combatiente de } \\
\text { Malvinas; vecino que sufrió inundación en 2013; } \\
\text { Comentarios analíticos: Manuel Carballeda, Candelaria Blotto y } \\
\text { conductor y co-conductora. } \\
\text { No hay móvil }\end{array}$} \\
\hline El programa tiene una version a & Si & \multicolumn{2}{|c|}{ La solapa del programa en la web contıene } \\
\hline
\end{tabular}




\begin{tabular}{|l|l|l|}
\hline Ia carta en un sitıo web & Precisiones & $\begin{array}{l}\text { Ubservaciones /aciaraciones } \\
\text { una seccion de notas destacadas, que consta } \\
\text { de las más salientes con texto, foto y audios } \\
\text { descargables. }\end{array}$ \\
\hline $\begin{array}{l}\text { Descripcion de la propuesta } \\
\text { comunicativa en las redes } \\
\text { sociales. }\end{array}$ & $\begin{array}{l}\text { En Iwitter, con lenguaje descontracturado, se } \\
\text { abordan temas atemporales, consejos o } \\
\text { sugerencias, con promos ligadas al mundo del } \\
\text { cine, la discografía o la tecnología. En } \\
\text { Facebook, se promocionan entrevistas } \\
\text { puntuales del sitio. }\end{array}$ & $\begin{array}{l}\text { Lotas que forman parte de las noticias } \\
\text { destacadas del programa en la web. }\end{array}$ \\
\hline
\end{tabular}

\begin{tabular}{|c|c|c|}
\hline \multirow[b]{2}{*}{ Disposición en estudio } & \multicolumn{2}{|l|}{ Interacciones desde exterior } \\
\hline & Ieletonica & Via WhatsApp \\
\hline $\begin{array}{l}\text { Adecuacion al distanciamiento de } \\
\text { acuerdo a metros cuadrados del } \\
\text { lugar. }\end{array}$ & $\begin{array}{l}\text { Conductores y columnistas nacen el } \\
\text { programa desde sus casas. La comunicación } \\
\text { se realiza a través de Hangout. El operador y } \\
\text { productora trabajan de manera presencial } \\
\text { desde la radio, cumpliendo con el } \\
\text { distanciamiento social requerido. }\end{array}$ & Mensajes de oyentes. \\
\hline
\end{tabular}




\section{Radio Estación Sur}

Radio Estación Sur busca construir una alternativa comunicacional dentro del espectro radial. Se define como un medio de comunicación popular que pertenece al Foro Argentino de Radios Comunitarias (FARCO).

En estos días cuentan, están trabajando una "programación de emergencia" por el Coronavirus. La situación les llevó a tomar la definición de reducir el personal a quienes son parte de la gestión, por tal motivo se levantó toda la programación exceptuando el programa "Codo a Codo" que se emite de 10 a 12 hs de lunes a sábados y de 17 a 19 hs durante toda la semana.

Esta alteración en la programación también modificó la cantidad de personas que están en el estudio durante la emisión del programa. Sólo hay un operador y una o dos personas en estudio dependiendo el día. Tanto productores como columnistas salen telefónicamente.

Este programa es el periodístico que tiene la radio e intercalan entre comentarios acerca de la actualización de datos de la situación del Coronavirus, entrevistas y columnas. Las entrevistas no son exclusivamente relacionadas al Coronavirus y la situación de la pandemia, pero en caso de no serlo, tocan el tema colateralmente.

Durante el programa además de las columnas y entrevistas, abordan el tema coronavirus con spots, tanto oficiales como de FARCO y propios. Además, por ser uno de los auspiciantes de la radio, pasan un institucional de la Municipalidad de Ensenada, también relacionado al Coronavirus.

Al estar asociados a FARCO, la radio cuenta con un boletín que se realiza entre las emisoras que componen esta federación. La característica es que todas las noticias que salen al aire van acompañadas de testimonios.

Por otra parte, la radio trabaja un informe regional que funciona como boletín, compuesto por 3 noticias y la situación climática. Este segmento de noticias está realizado por las emisoras comunitarias de La Plata y es emitido por emisoras que son parte de su producción.

Además de este programa, durante la semana se emiten otros dos de 19 a 21 hs. Los martes y jueves un programa de juegos, fundamentalmente para colaborar en la distención de les escuchas y sus niñes y lunes, miércoles y viernes y programa -también de entretenimientodonde abordan temas de interés general no asociados a lo coyuntural. Se puede escuchar hablar 
de temas como preparación de comidas, de bebidas, entre otros. Éste programa se realiza de manera remota en su totalidad (incluido el operador).

\section{Identificación de la radio}

\begin{tabular}{|c|c|}
\hline Nombre de la Emisora & FIV y1, / Radio Estacion sur \\
\hline IIpo de EmIsora & Comunitaria \\
\hline $\begin{array}{l}\text { I ransmite por } \\
\text { Streaming }\end{array}$ & Direccion: $11 /$ y 40 \\
\hline Redes Sociales & $\begin{array}{l}\text { www.tacebook.com/Estacionsury// } \\
\text { https://twitter.com/estacionsur917 } \\
\text { https://www.instagram.com/estacionsur91.7/ } \\
\text { https://www.youtube.com/channel/UCw59xUL7yvj8UM3QqGeLCDg }\end{array}$ \\
\hline Nombre del Programa a analizar. & Codo a Codo \\
\hline Intormativo. Nombre & Intormatıvo RegIonal/Intormatıvo FARCU \\
\hline
\end{tabular}

\section{El programa}

\begin{tabular}{|c|c|c|c|}
\hline & Precisiones & \multicolumn{2}{|c|}{ Ubservaciones /aciaraciones } \\
\hline Nombre & Codo a Codo & \multicolumn{2}{|l|}{ Se reallza en 2 norarıs } \\
\hline Horario & 10 a 12 y $1 /$ a $19 \mathrm{~ns}$ & \multirow{2}{*}{\multicolumn{2}{|c|}{$\begin{array}{l}\text { Columnistas y productores trabajan } \\
\text { desde sus casas }\end{array}$}} \\
\hline Integrantes del Equipo y Roles & $\begin{array}{l}\text { Rotativos. En piso una o dos personas y un } \\
\text { operador. }\end{array}$ & & \\
\hline Contenidos desarrollados & \multicolumn{2}{|c|}{$\begin{array}{l}\text { Coronavirus todos Ios dias. Lo trabajan con comentarıos, material de archivo, } \\
\text { entrevistas. Además tocaron temas como fumigación en Santiago del Estero, } \\
\text { experiencias musicales virtuales, situación de los comedores populares, tramites } \\
\text { a distancia de diferentes dependencias estatales y privadas, conmemoración de } \\
\text { la guerra de Malvinas, situación de PyMEs, situación de Pueblos Originarios en } \\
\text { Salta, situación del programa FinEc, }\end{array}$} & \\
\hline Genero & Intormativo & & \\
\hline Formato & Magazıne & & \\
\hline Duracion & $4 \mathrm{~ns}$ & 2 de manana 2 de tarde & \\
\hline Breve descripcion tematica & $\begin{array}{l}\text { Programa Intormatıvo necho por el equipo permane } \\
\text { son parte de la gestión de la radio podían participar } \\
\text { Al ser el único programa fijo de la emisora, se realiza } \\
\text { y de } 17 \text { a } 19 \text { hs. Los equipos también cambian entre } \\
\text { la de la tarde. }\end{array}$ & $\begin{array}{l}\text { nte de la radio. Quienes no } \\
\text { ero sólo desde sus casas. } \\
\text { en dos horarios: de } 10 \text { a } 12 \\
\text { la emisión de la mañana y }\end{array}$ & \\
\hline $\begin{array}{l}\text { Entrevistados } \\
\text { Comentarista }\end{array}$ & $\begin{array}{l}\text { Entrevistados Marcelo (Pantalon Cortito), Angel } \\
\text { Cura Opción por los pobres, Dip Nac por Salta - Ver }\end{array}$ & $\begin{array}{l}\text { Strapassone (Mrocase-vC), } \\
\text { rónica Caliva, Ernesto Movili }\end{array}$ & \\
\hline
\end{tabular}




\begin{tabular}{|c|c|}
\hline & Ubservaciones /aciaracio \\
\hline $\begin{array}{l}\text { MoVII } \\
\text { Conductor } \\
\text { Otros. Precisar }\end{array}$ & $\begin{array}{l}\text { DDHH CECIM-LP), Alejandro Pon (Radio Nacional), Diego Boris (titular del } \\
\text { Instituto Nacional de la Música), Eduardo Berrozpe (Bancaria), Gudi González } \\
\text { (por sistema Seguimos Educando) } \\
\text { Comentarista: Suele ser quien conduce el programa. Durante la semana } \\
\text { analizada no hubo comentaristas que salgan telefónicamente a excepción de } \\
\text { quien abordó la columna internacional que habló sobre la escalada de tensiones } \\
\text { entre Venezuela y EEUU. } \\
\text { Móvil: No tienen } \\
\text { Conductor: La conducción rotó de acuerdo al día. Dada la particularidad del } \\
\text { programa especial se armaron equipos que rota durante los días de la semana. }\end{array}$ \\
\hline $\begin{array}{l}\text { El programa tiene una version a la } \\
\text { carta en un sitio web }\end{array}$ & No, el programa no tiene redes propias. Utillzan las redes de la radio. \\
\hline $\begin{array}{l}\text { Descripcion de la propuesta } \\
\text { comunicativa en las redes } \\
\text { sociales. }\end{array}$ & $\begin{array}{l}\text { Al ser un programa especial por la situacion, el manejo de redes se hace } \\
\text { directamente desde las cuentas de la emisora. }\end{array}$ \\
\hline
\end{tabular}

\section{El informativo}

\begin{tabular}{|c|c|c|}
\hline & Precisiones & Ubservaciones/aclaracıones \\
\hline Nombre & Intormatıvo Regional & \\
\hline Boletınes & $\begin{array}{l}\text { Intormativo Regional: (variable, pero siempre a la nora) } \\
\text { Trataron el tema coronavirus y sus situaciones } \\
\text { colaterales. Generalmente alguna de las } 3 \text { noticias } \\
\text { estaba relacionada con el COVID-19. Algunos días } \\
\text { tenían recortes de audio. En otros, el recorte era sobre } \\
\text { otro tema. }\end{array}$ & $\begin{array}{l}\text { El horarı varia. No todos los dias se } \\
\text { realizaba al mismo horario. En los días que } \\
\text { fue más constante se lo podía escuchar } \\
\text { cada hora. }\end{array}$ \\
\hline MInI panoramas & No tlenen & \\
\hline Panoramas & $\begin{array}{l}\text { Intormativo FARCU: Generalmente se abordan temas de } \\
\text { distintas partes de la Argentina. No tanto en relación con } \\
\text { el COVID-19 sino a situaciones colaterales como } \\
\text { decisiones de gobiernos provinciales y/o municipales, } \\
\text { cómo afecta a determinados sectores, entre otros. }\end{array}$ & \\
\hline
\end{tabular}




\section{FM La Redonda}

Una radio de fútbol sin fútbol

La FM La Redonda desde 1997 es, según su propia definición, "la radio deportiva de la ciudad". Tiene una programación en la que si bien hay envíos de actualidad e información general sobresalen aquellos que se refieren al presente futbolístico del Club Estudiantes de La Plata y del Club de Gimnasia y Esgrima La Plata, con cronistas que salen al aire desde los entrenamientos de estos equipos a toda hora.

Durante la primera semana de aislamientos social obligatorio la radio decidió levantar toda la programación y pasar música, pero en el período analizado volvió al aire, aunque con algunas modificaciones en su grilla y la dificultad de hablar de fútbol cuando no solo no hay fútbol sino que además no hay entrenamientos ni certezas sobre cuándo vuelve la actividad.

Además sumó una serie de mensajes institucionales (artística) que llevan situaciones del fútbol y el relato deportivo a la viuda cotidiana en tiempos de cuarentena: un pateador que pide distancia a la barrera, el árbitro que se lava las manos.

El programa de la primera mañana, "Puntapié inicial", que va todos los días de 6 a 8, suspendió sus envíos y la transmisión comenzó a las 8 con "Golpe de Suerte", programa periodístico informativo que va hasta las 12 del mediodía.

A las 12 empieza "El Equipo Deportivo" con staff reducido y participación telefónica de los cronistas, que si bien habitualmente salen por teléfono por estar en los predios donde entrenan los equipos de la ciudad en esta semana lo hicieron desde los lugares donde cumplen el aislamiento social obligatorio: Fernando Serrano con la actualidad de Estudiantes, Facundo Haché con Gimnasia, Mariano Twerski en AFA.

A las 14 comienza "Siesteros", un magazine que habitualmente es conducido por una mesa de tres periodistas y una locutora, pero en este período tiene solo a uno de ellos, Martín Daher, y a Viviana Vila, Hernán Castro Balbi y Marisa Figini participando por teléfono, al igual que los columnistas.

A las 17, el programa "La Escudería" que compra su espacio y va hasta las 18 dejó su lugar para un espacio sin nombre a cargo de Federico Serra (de "El Equipo Deportivo"), hasta las 19, suspendiendo también su salida al aire "El Superclásico", el programa que habitualmente se dedica a la presencia de Boca Juniors y River Plate. 
A las 19 llego el momento del último programa del día, "El Equipo Deportivo, segunda edición", con Martín Mendinueta y Martín Ortiz en el estudio y la participación telefónica de los mismos cronistas que en la primera edición al que se suma Martín Pertierra, habitual co conductor, también por teléfono como columnista.

Desde las 21 la radio emite música hasta el inicio del día a las 8.

Más allá de la reducción del staff y las salidas por teléfono otros cambios notorios en la habitualidad de la radio es que el servicio informativo sale grabado desde la casa de cada uno de los locutores, se incorporó el pase entre programas y artística alusiva al aislamiento social. El servicio informativo está anunciado como "Las noticias destacadas en eldia.com" y siempre está conformado exclusivamente por noticias del mencionado portal. Esta presentación de noticias tiene la particularidad de salir a veces como panorama informativo a las horas en punto y otras veces ser anunciadas por el conductor del programa y leídas por el locutor en piso como parte del programa que está al aire.

Es interesante tener en cuenta que así como se anuncia desde la artística del servicio informativo la única fuente de información será el portal del diario que encabeza al grupo periodístico.

En gran parte de la programación los cambios se notaron en términos de producción y realización: no es lo mismo hacer un magazine con dos productores y cuatro o cinco personas sentadas en el estudio que hacerlo con solo un productor, un operador y un conductor y el resto por teléfono, pero fue en "El Equipo Deportivo" donde más se vieron los cambios en cuanto a los temas abordados, al no haber fútbol la oferta informativa tuvo que virar hacia los hechos del momento, como la pandemia en sí, el aislamiento social y obligatorio y la situación de los argentinos, en muchos casos platenses y deportistas, varados en el extranjero.

En "El Equipo Deportivo" el lunes 30, las entrevistas fueron a un jugador de rugby de la ciudad de La Plata varado en Cuba junto a un equipo con el que había ido a participar de algunos partidos y encuentros de difusión del deporte, a una platense varada en Tailandia, el cronista de Estudiantes habló de la instalación de una carpa en el predio que ocupa el estadio Jorge Luis Hirschi y su par de Gimnasia sobre las dificultades del club para pagar los sueldos a sus empleados.

El martes 31 sí tuvieron una entrevista cercana al futbol: al presidente de Gimnasia Gabriel Pellegrino, pero comenzó con preguntas referidas a la actividad profesional del entrevistado ya 
que es empresario farmacéutico, el miércoles abrieron con el Secretario de Convivencia Urbana de La Plata Roberto Di Grazia por las clausuras en el Mercado Central y Héctor Polino, defensor de los derechos de los consumidores y el jueves 2, Día del Veterano y de los Caídos en la guerra de Malvinas, tuvieron una larga entrevista con Ernesto Alonso del CECIM La Plata. Como vemos, el fútbol estuvo lejos.

Siesteros es otro tipo de programa: se trata de un magazine conducido por Hernán Castro Balbi y Martín Daer, que se vuelca hacia la información deportiva, con dos locutores Marisa Figini y Alejandro Saikevich, y con la participación de Viviana Vila. El programa tiene distintos columnistas, algunos con días fijos y otros que consultan eventualmente, entrevistas y más música que otros momentos de la programación.

En tiempo de cuarentena el único conductor en piso fue Martín Daer, con el resto de los integrantes de la mesa por teléfono, al igual que los columnistas y los entrevistados. Entre los columnistas están Carlos Arcuri en espectáculos, Florencia Molina con la Liga Platense, y Fernando Serrano y Facundo Haché con los equipos de fútbol de la ciudad y otros.

Allí lo más llamativo se dio el miércoles: luego del habitual y extendido pase con el programa anterior el conductor Martín Daher interrumpió la cortina del programa para poner al aire al Presidente Alberto Fernéndez, que en ese momento estaba hablando en la reinaguración de un sanatorio junto a Hugo Moyano.

El resto de la semana el programa, más allá de las diferencias en cuanto a la realización técnica, siguió por carriles casi normales, con columnistas y entrevistados que ayudaron a dar consejos para sobrellevar el aislamiento social obligatorio.

En cuanto al uso de las redes sociales la radio en su Facebook y Twitter adelanta a los programas que están por comenzar y eventualmente a los columnistas y entrevistados que están por salir al aire, lo mismo hace en su página web. Ni la página ni las redes postean entrevistas hechas en los programas, al menos durante el período estudiado.

* El informe de Avance describe parcialmente las estrategias de las seis emisoras escuchadas, durante una semana y haciendo foco en un segmento de su programación y el servicio de noticias. Se ha comenzado con la segunda parte de entrevistas a funcionarios de la gestión, comunicadores y profesionales técnicos. 


\section{Notas}

i María Jesús Espinosa De Los Monteros. La radio en la crisis de la Covid-19. La voz contagia emociones en tiempos de crisis y sirve como refugio para los más mayores. El País, 17 MAR 2020 https://elpais.com/elpais/2020/03/15/dias_de_vino_y_podcasts/1584271315_152798.html?ssm=whatsa pp

ii 25 de Marzo 2020 http://www.gorkazumeta.com/2020/03/la-radio-lidera-el-ranquin-de-medios.html?m=1

iii Agustín Espada, Medios en cuarentena. Letra P. 24/03/2020 https://www.letrap.com.ar/nota/2020-3-24-14-50-0-medios-encuarentena/amp? twitter_impression=true

iv Marina Zucchi. La radio en tiempos de coronavirus: cumple 100 años y se vuelve más fuerte. Clarín. 20/03/2020 https://www.clarin.com/espectaculos/radio-tiempos-coronavirus-cumple-100-anos-vuelvefuerte_0_M9GrIRNnJ.html

v Cebrián Herreros, M. Información radiofónica y mediación técnica, tratamiento y programación. 1ra Edición. Madrid, 1994 